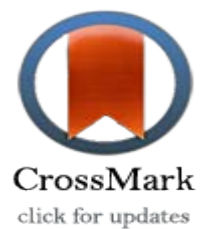

\title{
The effect of Concurrent cerebral transcranial direct current stimulation and neuromuscular coordination exercises on balance elderly people
}

\author{
*Mousavi Sadati SK ${ }^{1}$, Tajik N²
}

1- Assistant Professor of Motor Behavior, Department of Sport Science and Physical Education, East Tehran Branch, Islamic Azad University, Tehran, Iran (Corresponding Author)

Email: drmousavisadati@gmail.com

2- MSc of motor behavior, East Tehran Branch, Islamic Azad University, Tehran, Iran.

\begin{abstract}
Introduction: Frequent falls in the elderly have a direct relationship with postural control and balance. The purpose of the present study was to investigate the effect of Concurrent cerebral transcranial direct current stimulation and neuromuscular coordination exercises on balance elderly people.

Method: This study was an experimental, pre- and posttest design. The participants of this study were 24 elderly who were selected by convenience sampling and randomly assigned to two groups ( $\mathrm{n}=12$ ). After a preliminary assessment of equilibrium parameters by Computerized Dynamic Posturography apparatus, "Intervention" group received direct current stimulation over the cerebellum at 2mA and "Control" group received sham stimulation, twenty minutes each session in five days during two weeks. At each session, immediately after stimulation, participants performed half-hour equilibrium exercises on the Huber apparatus. After completing five sessions, the variables were re-measured. Data analysis performed using MANCOVA and ANCOVA and SPSS 23 software.

Results: The results of this study showed that current direct stimulation of the cerebral had significant effect on the postural control equilibrium variables in the first and fourth sensory condition $(\mathrm{P}<0.05)$. However, it did not have a significant effect on the stability of the elderly in the second, third, fifth, sixth sensory condition and composite balance $(\mathrm{P}>0.05)$. In addition, cerebral electrical stimulation with balance training improved postural control performance of visual system $(\mathrm{P}<0.05)$, but postural control performance of somatosensory system, vestibular system, and visual preference did not significantly improve $(\mathrm{P}>0.05)$.

Conclusion: The results of this study showed that cerebral TDCS with balance training has little beneficial effects on postural control and balance of elderly people and can, to a lesser extent, facilitate motor learning and improve motor adaptation.
\end{abstract}

Key words: Transcranial Direct Current Stimulation, postural balance, aged.

Received: 15 November 2019

Accepted: 21 December 2019 


\section{تاثير همز مان تحريك مستقيم الكتريكى فر اجمجمه مغز و تمرينات هماهنكى عصبى عضلانى بر تعادل سالمندان

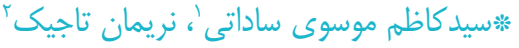

ا - استاديار رفتار حركتى، كروه تربيت بدنى و علوم ورزشى، واحد تهران شرق، دانشخاه آزاد اسلامى تهران، ايران (نويسنده مسئول)

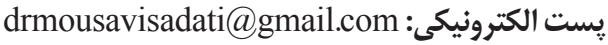
r- كارشناس ارشد رفتار حركتى، واحد تهران شرق، دانشگاه آزاد اسلامى تهران، ايران.

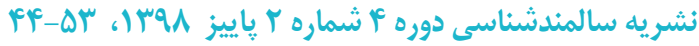

مقدمه: افتادن هاى مكرر در سالمندان ارتباط مستقيم با كنترل وضعيت ايستاده و تعادل دارد. هدف مطالعه حاضر بررسى تاثير

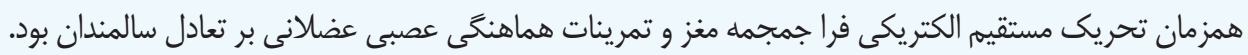

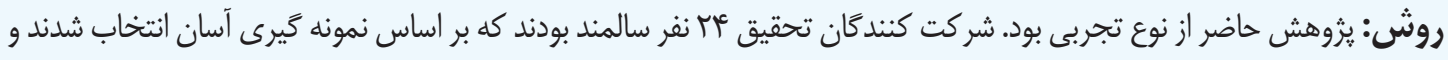

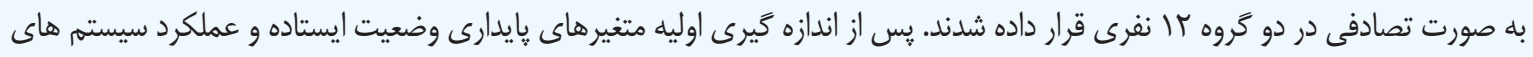

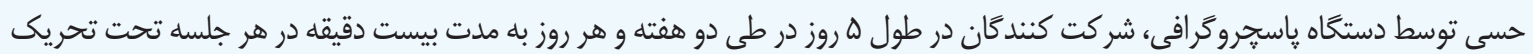

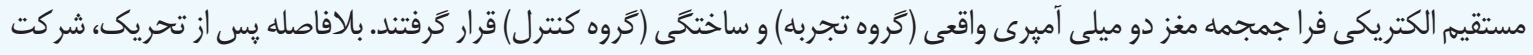

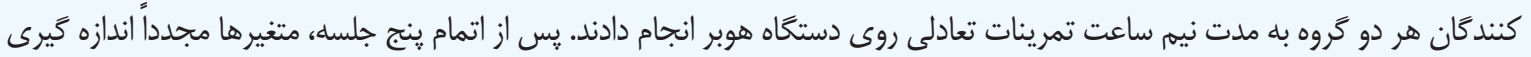

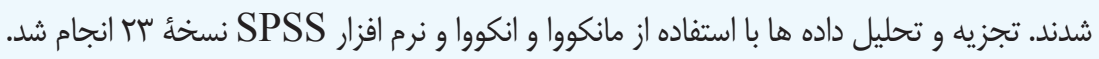
يافته ها: نتايج نشان داد كه تحريك مستقيم الكتريكى مغز از روى جمجمه همراه با تمرينات تعادل به طور معنادارى بايدارى

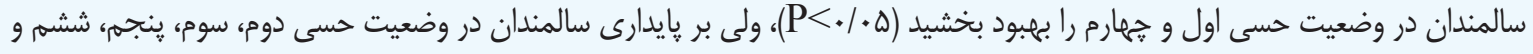

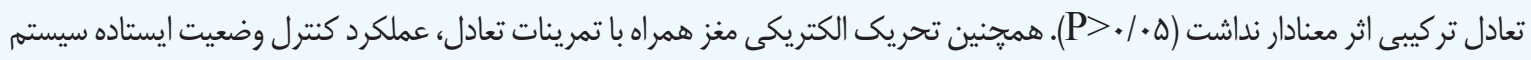

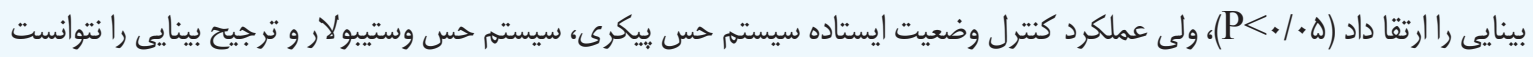

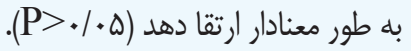
نتيجه كَيرى: نتايج تحقيق نشان داد كه تى دى سى اس مخى همراه با با تمرينات تعادلى بر كنترل وضعيت ايستاده سالمندان تاثيرات

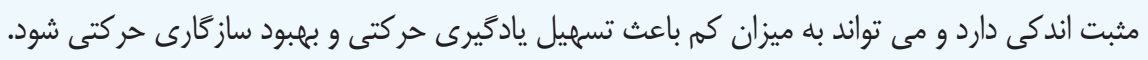
كليد وازه ها: تحريك مستقيم الكتريكى فرا جمجماه، تعادل، سالمندان.

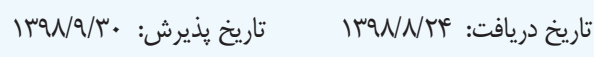

حس ييكرى (حس عمقى) و وستيبولار است. به منظور فراهم آوردن

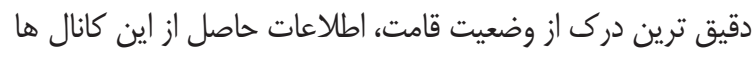

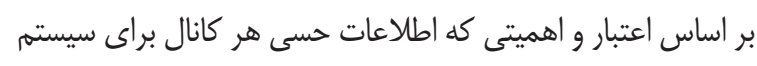

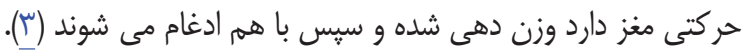

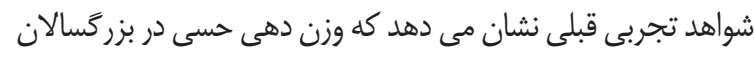

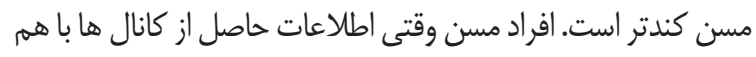
در تضاد هستند در مقايسه با جوانان بويزه در اولين كوشش، احتى احتمال بيشترى وجود دارد كه سقوط كنند (أ).)

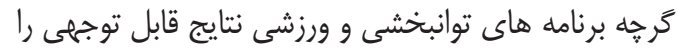

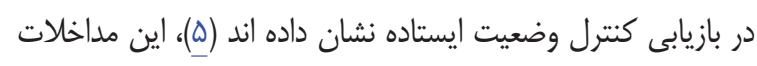

\section{مقلdod} كنترل تعادل يك كار حركتى بِيجيده است كه توسط كروه هاى عصبى در نخاع، ساقه مغز، مخجه و قشر مغز كنترل مى شود

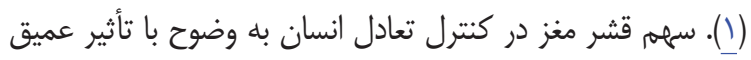
ضايعات قشر مغز بر توانايى حفظ تعادل ايستاده نشان داده شده است. شواهد جديد حاكى از اين است كه قشر حركتى (M1) مغز براى

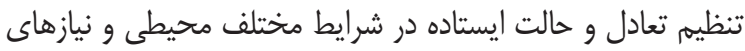

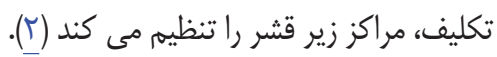

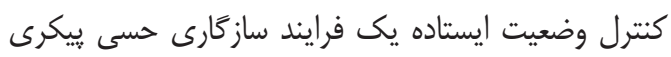
است كه مستلزم ادغام مداوم اطلاعات حسى از سه كانال بينايى، 
است كه تحريك كاتدى قشر ييش ييشانى خلفى جانبى با سركوب فعاليت حافظه كارى باعث تقويت يادگيرى حركتى ينهان مى شود

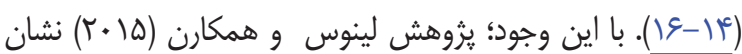
داد كه tDCS آندى تعداد خطاها را فقط در شرايط هماهنخى دو طرفه كاهش مى دهد، اما هيج تغييرى در زمان واكنش نمى دهد و تعداد خطاها در شرايط هماهنكى يك طرفه و سه اندام اندام ايجاد

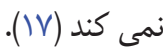

كامينسكى و همكاران (Y. V. (Y) دريافتند كه يك جلسه تحريك مستقيم الكتر يكى فراجمجمه آندى مغز (a-tDCS) افراد

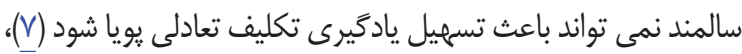

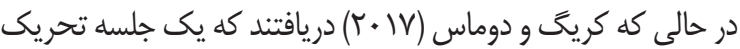
مستقيم الكتريكى فراجمجمه آندى مغز (a-tDCS) افراد سالمند

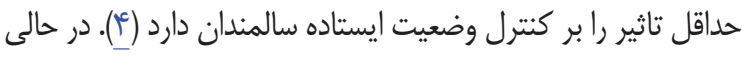

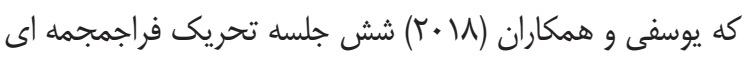
آندى (a-tDCS) مخ همراه با تمرينات وررزشى را براى كنترل

وضعيت ايستاده بسيار سودمند كزارش كرده اند (1). شواهدى وجود دارد كه افزايش تعداد جلسات استفاده از تى دى سى اس، مىتواند اثر بخشى آن را بيشتر كند (أl)، در تحقيق حاضر فرض بر اين است كه استفاده همزمان از تحريك مستقيم

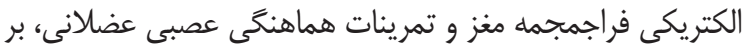

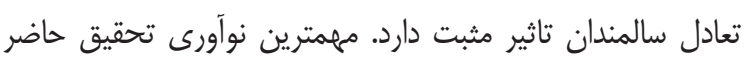

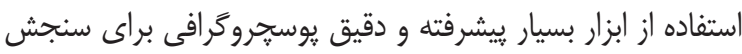
تعادل و دستَّاه هوبر براى انجام تمر ينات هماهنگى عصبى عضلانى

\section{روش مطالكه}

يزووهش حاضر تجربى و از نوع ييش آزمون - هِ آزمون بود.

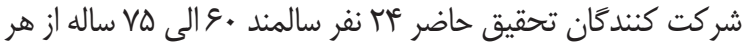
دو جنس زن و مرد بودند كه از بين سالمندان شهر پاكدشت بر اساس معيارهاى ورود و با نمونه كَيرى آسان انتخاب شدند و با كَمارش تصادفى در دو گروه rا نفرى تجربى و rا نفرى كنترل قرار داده شدند. معيارهاى ورود در تحقيق عبارت بودند از: سالم بودن در زمينه هاى اسكلتى، عضلانى، عصبى، شناختى، عدم وجود هر كونه بيمارى

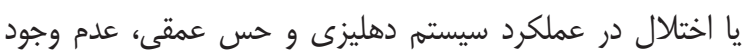

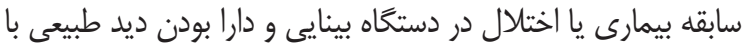
يا بدون عينك، عدم استفاده از داروهايى كه دستخاه عصبى و كنترل وضعيت ايستاده را تحت تاثير قرار مى دهند، عدم سابقه بيهوشى در צ ماه كذشته، داشتن استقال كامل در حركت و انجام فعاليت هاى روزمره بدون استفاده از وسايل كمكى، و عدم وجود سابقه ورزش و
به طور معمول زمان و هزينه هاى زياد نياز دارند و ممكن است فقط

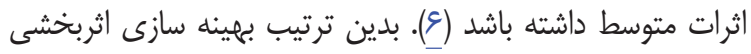
اين مداخلات با كاهش زمان و تلاش لازم براى دستيابى به نتايج سودمند، براى جامع سالمندان در سراسر جهان بسيار مهرم است. كاهش تعادل باعث افتادن هاى مكرر در سالمندان مى شود (V). ترس از افتادن به عنوان يك وضعيت روانى محدود كننده فعاليت هاى فيزيكى، در ميان عوامل متعدد تهديد كننده سلامت سالمندان،

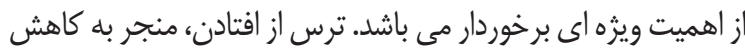

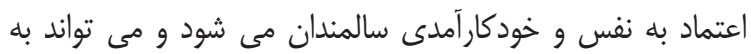
عنوان مانعى براى فعاليت فيزيكى مناسب مطرح شود (1). كنترل وضعيت ايستاده و تعادل تقريباً براى تمام جنبه هاى زندگى روزمره ضرورى است. اختلال در كنترل وضعيت ايستاده ناشى از محدوديت هاى عملكردى اساسى دوران سالمندى و بيمارى هاى ياتولوزيك مانند سكته مغزى، بيمارى يار كينسون يا مولتييل اسكلروز است (9-1(). تر جه برنامه هاى توانبخشى و ورزشى نتايج قابل توجهى را در بازيابى كنترل وضعيت ايستاده نشان داده اند، اين مداخلات به طور معمول زمان و هزينه هاى زياد نياز دارند و ممكن

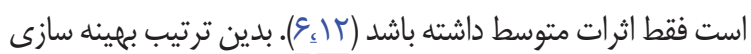
اثربخشى اين مداخلات با كاهش زمان و تلاش لازم براى دستيابى به نتايج سودمند، براى جامع سالمندان در سراسر جهان بسيار مهمه است. ترس از افتادن به عنوان يك وضعيت روانى محدود كننده فعاليت هاى فيزيكى، در ميان عوامل متعدد تهديد كننده سلامت سالمندان، از اهميت ويزه ایى برخوردار مى باشد. ترس از افتادن،

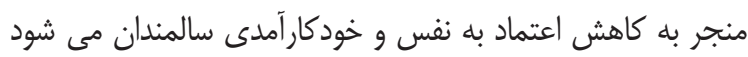

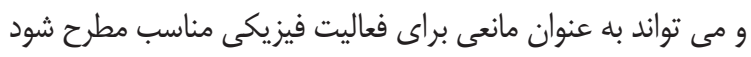
(^) ثبات وضعيت ايستاده و تعادل حاصل تعامل يوياى درون دادهاى في فئل حس عمقى (ناشى از دوى هاى عضلانى، اندام هاى وترى كلثى و كيسول مفصلى)، حس دهليزى گَوش داخلى، حس بينايى و مكانيزم هاى عصبى نخاعى، زير قشرى و قشرى است ("َّ). تحريك مستقيم الكتريكى فرا جمجه مغز (tDCS) روشى فئرئ غير تهاجمى است كه امكان تعديل بركشت يذير فعاليت مناطق

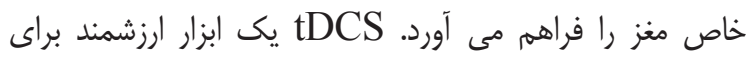
سازماندهى رفتار مغز در حوزه هاى شناختى، حركتى، اجتماعى و عاطفى فراهم آورده است. در جوامع سالم نشان داده شده است كه

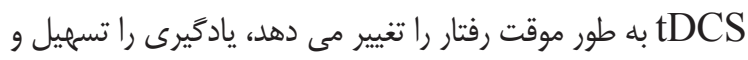
اجراى تكليف حركتى را تقويت مى كند. به عنوان مثال، نشان داده شده است كه تحريك أندال باعث بهبود تشخيص جهره مى شعى شود يا باعث مهار ياسخ هاى تهاجمى مى شود. در حالى كه نشان داده شده 


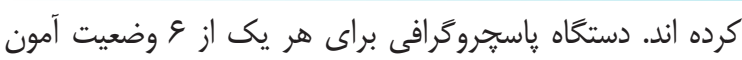

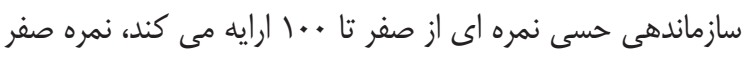

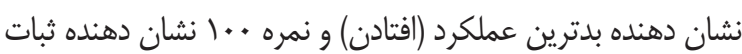
خوب و حداقل تاب خوردن است (זr)، ع) دستگاه تى دى سى اس، كه با بهره گيرى از اين دستخاه، يك جريان مستقيم الكتريكى فرا

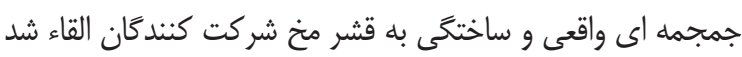

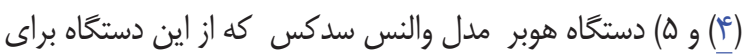
بهبود هماهنگى عصبى - عضلانى استفاده شد. كول اندره و همكاران عنوان كردند كه اين دستكاه علاوه بر تقويت عضلات و اصلاح وضعيت بدنى، به طور همزمان منجر به باز آموزى حسى و و

تقويت كنترل حركتى نيز مى گردد (سٓ). به منظور رعايت اخلاق در تحقيق، اهداف يُوهش و مراحل تحقيق، و ملاحظات ايمنى مربوط به استفاده از تى دى سى اس

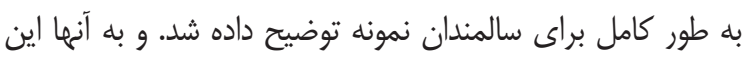

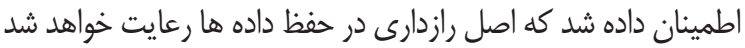

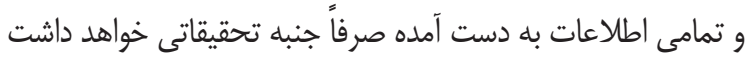
و پِس از آن، فرم هاى رضايت نامه توسط آنان امضا شد. به منظور اجراى يزوهش ابتدا فرم ارزيابى سلامت هر داوطلب

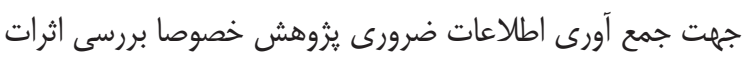
جانبى تى دى سى اس توسط آزمونكر از طريق مصاحبه حضورى

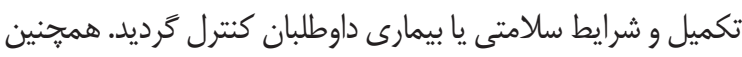

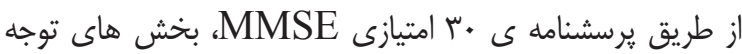
و محاسبه، حافظه، زبان، توانايى اجراى فرمان هاى ساده و جهت

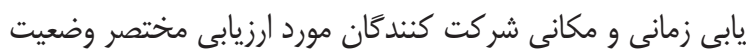

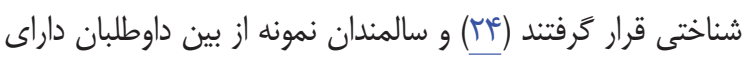

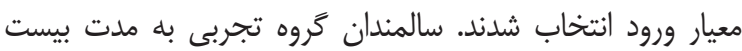

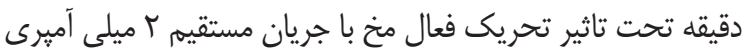

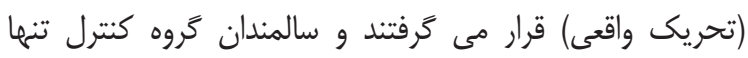
به مدت • ب ثانيه تحت تاثير تحريك فعال مخ بار با جريان مستقيم

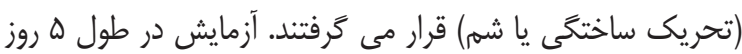
در خلال دو هفته و هر روز به مدت بيست دقيقه انجام شد (هآ، آ). فاصله زمانى ^^^ ساعت بين جلسات متوالى رعايت شد و تمام افراد

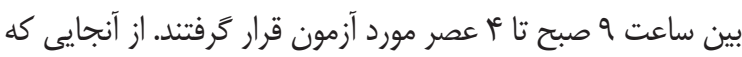
كروه كنترل تحريك ساختخى دريافت مى كردو تحريك ساختخى

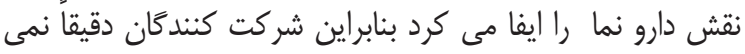

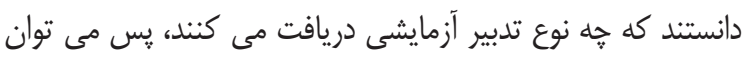
كفت كه اين مطالعه به صورت يك سويه كور انجام شد. بر اساس يروتكل مورد استفاده در اين يُوهش، يك جريان مستقيم الكتريكى ليك
فعاليت هاى بدنى منظه. معيارهاى خروج آزمودنى ها از تحقيق؛ وجود بيمارى هاى مغز و اعصاب مثل صرع كه باعث بالا رفتن خطر مانى

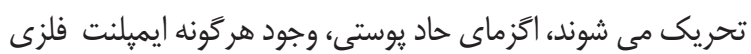
در مغز، وجود سابقه اختلال در تعادل و سر ميجه وضعيتى مكرر و و

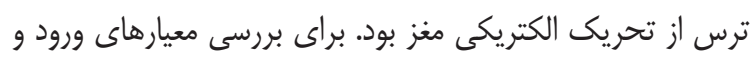

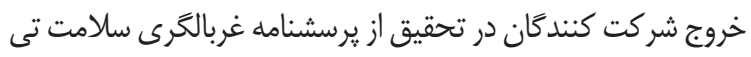
دى سى اس و تى اى سى اس و نسخه فارسى آزمون كوتاه وضعيت ذهنى استفاده شد (19). ابزارهاى مورد استفاده در يزوهش عبارت بودند از: () يرسشنامه

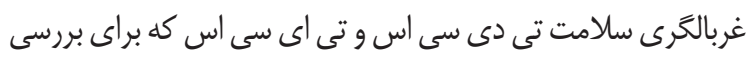
شاخص هاى مورد نياز جهت ايمن و مناسب بودن استفاده از تى دى سى اس براى شركت كننده ها استفاده شد. يرسشنامه غربالترى

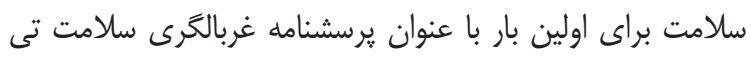

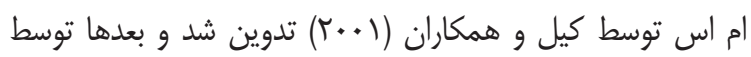
محققين و موسسات ديخر از جمله دانشخاه بيرمنگام (ها + ب) تكميل

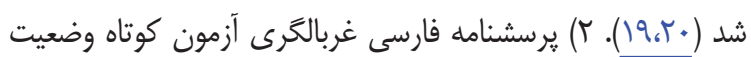

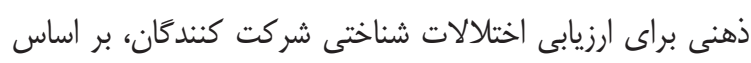
اين فرم كسب نمره يايين تر از سٓ معيار خروج شركت كنندكان

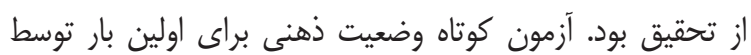
مارشال فولستين (19VD) به منظور غربالكرى زوال عقل ابداع شد.

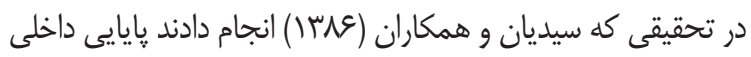

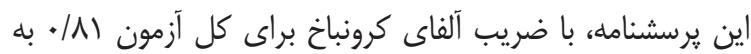
دست آمد و با استفاده از منحنى ROC نمره با ب به عنوان نقطه

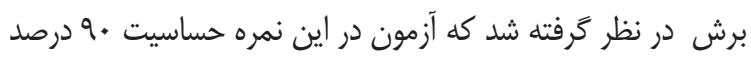

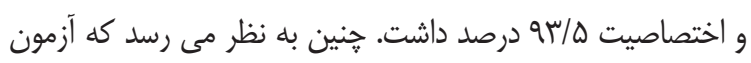
كوتاه وضعيت ذهنى فارسى قابليت و ويايايى مناسبى داشته و با نمره

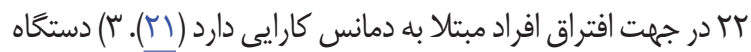
ياسجروگر افى يوياى كاميبوترى مدل اكويى تست ساخت شركت

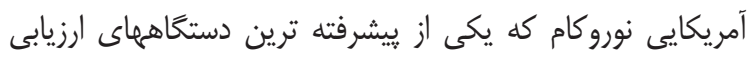

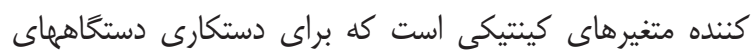
حسى مؤثر در كنترل وضعيت ايستاده به كار مى رود. اين دستكاه،

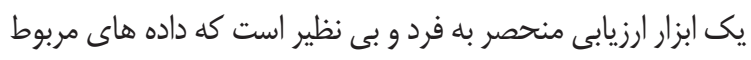
به كنترل وضعيت ايستاده را به صورت كمى فراهم كرده و براى تجزيه و تحليل مكانيزم هاى نوسان مرتبط با سن ابزار مناسبى به نظر مى رسد، از اين دستخاه به طور گسترده در تحقيقات براى بررسى متغيرهاى مربوط به تعادل و كنترل وضعيت ايستاده استفاده

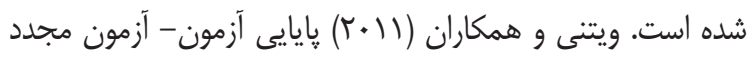

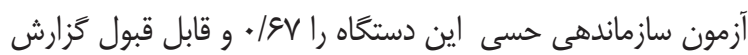


روش بركزار شد و در جلسه پِنجم، پِ از تمرينات هوبر و متعاقب استراحت ها دقيقه اى، آزمون سازماندهى حسى اجرا شد و و نتايج مربوطه (يس آزمون) ثبت كرديد.

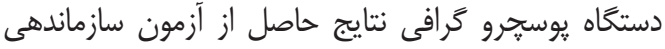
حسى را در قالب كزارش نمرات تعادل و نمرات حسى ارايه

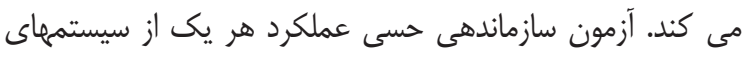
حس بيكرى، دهليزى و بينايى را در كنترل وضعيت ايستاده مورد ارزيابى قرار مى دهد. اين آزمون داراى ؤوضعيت است. طبق يروتكل تعريف شده، در هر يك از اين وضعيت ها، آزمون ها بّ بار انجام إمام

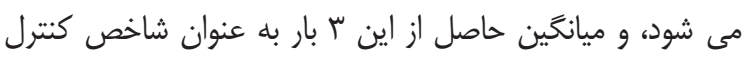

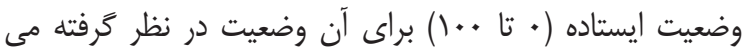
شود. در آزمون سازماندهى حسى صفحه هاى نيرو (سطح اتكا) در سه وضعيت اول ثابت هستند و در سه وضعيت ديگر در جهت هاى قدامى و خلفى حركت مى كنند ولى مرجع بينايى در جهار وضعيت

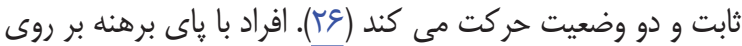

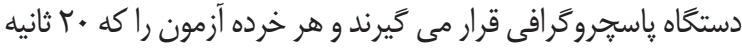
به طول مى انجامد را با فواصل استر احتى يكسان و دقيق به تعداد سه

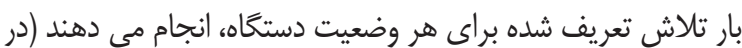
مجموع \1 تلاش). خلاصه اى از شش شرايط آزمون سازماندهى

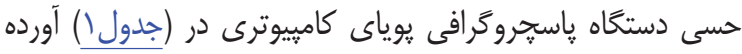
شده است و در (جدولr) نحوه محاسبه نمرات حسى (عملكرد

$$
\text { سيستم هاى حسى) آورده شده است. }
$$

فرا جمجمه اى دو ميلى آمبرى با قرار دادن الكترود فعال آند روى خط طولى - ميانى سر روى قشر حركتى ياها در منطقه حركتى اوليه و الكترود مرجع كاتد روى نقطه اينيون (برآمدگى استخوان پِّ سرى

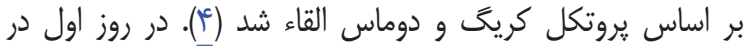
ابتداى جلسه و ييش از اعمال مداخله ى درمانى، آزمون سازماندهى

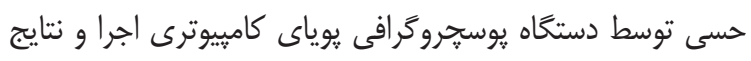
ثبت شد. در اين آزمون متغيرهاى كينتيك كنترل وضعيت ايستاده نمونه ها شامل دامنه جابجايى مركز فشار، سرعت جابجايى مركز فشار و استراتزى كنترل قامت در و وضعيت دستكارى سيستمهاى حسى درَّير در كنترل وضعيت ايستاده مورد ارزيابى قرار كرفتند. ڤِ از ثبت نتايج آزمون سازماندهى حسى و متعاقب يك استراحت ب دقيقه اى، شركت كننده تحت تاثير تى دى سى اس واقعى و يا

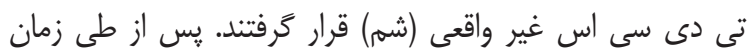

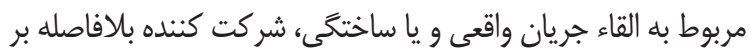
روى دستخاه هوبر مستقر شده و به انجام تمرينات حسى - حركتى مى يرداخت. مدت زمان تقريبى هر جلسه تمرين بر روى اين دستاءهاه

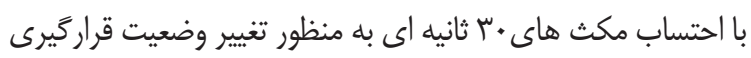
بر روى يلت فرم •ب دقيقه بود. سطح پايه تمرينات از نمرات سرعت

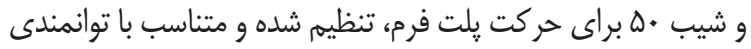
عصبى - عضلانى شركت كننده در هر جلسه حدود هـ افزايش مى يافت. هر شركت كننده عملكرد تعادل خود را روى دستخاه تنظيه مى كرد و يزوهشكَ نيز تلاش مى كرد با باستفاده از باز بازخورد بينايى و شنوايى، وضعيت ايستاده فرد را اصلاح كند. ينج جلسه، با همين

جدول ا: خلاصه اي از شش وضعيت آزمون سازماندهى حسى دستخاه ياسجروگرافى يوياى كامييوترى

\begin{tabular}{|c|c|c|c|c|c|}
\hline 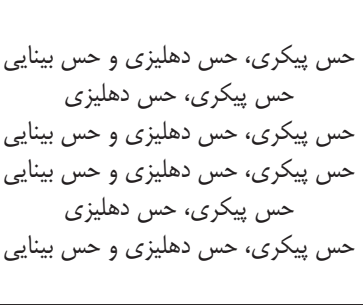 & 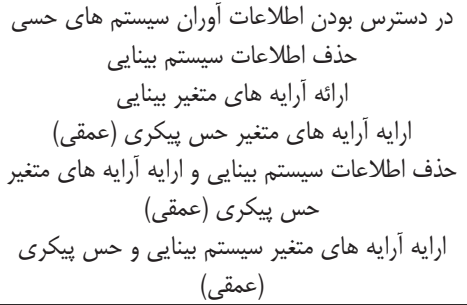 & ثتابت ثابت ثابت ثتح ثابت & ثبات متبات & باز باز باز باز & وضع وضعيت حسى حسى دوم اول \\
\hline
\end{tabular}

جدول Y : توصيف و نحوه محاسبه نمرات عملكرد حسى آزمون سازماندهى حسى

\begin{tabular}{|c|c|c|}
\hline نمرات وضعيت r تقسيم بر نمرات وضعيت I & توانايى فرد در استفاده موثر از درون دادهاى حس ييكرى & نمره عملكرد حس يكري \\
\hline نمرات وضعيت f أتقسيم بر نمرات وضعيت ا & توانايى فرد در استفاده موثر از درون دادهاى حس بينايى & نمره عملكرد حس بينايي \\
\hline نمرات وضعيت ه تقسيم بر نمرات وضعيت 1 & توانايى فرد در استفاده موثر از درون دادهاى حس دهليزى & نمره عملكرد حس دهليزى \\
\hline مجموع نمرات وضعيت س و و تقسيه بر مجموع نمرات وضعيت & ميزان اعتماد فرد به درون دادهاى بينايى، حتى زمانى كه درون دادهاى & نمره ترجيح حس بينايى \\
\hline
\end{tabular}




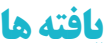

ميانكين و انحراف معيار ويزَّيهاى جمعيت شناسى شركت

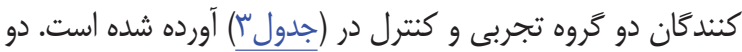

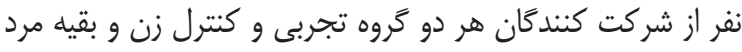

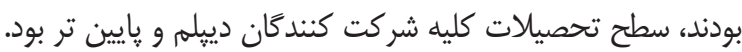
يافته ها نشان مى دهد اختلاف معنادارى بين ويثَّيهاى جمعيت

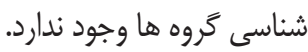

تجزيه و تحليل داده ها با استفاده از نرم افزار SPSS نسخهُ سץ انجام شد. سطح معنى دارى ه.٪ بررسى نرمال بودن توزيع داده ها از آزمون شإيبروويلك، يكسان

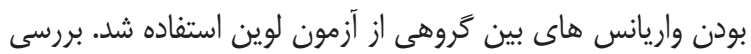

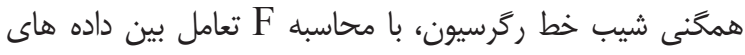
متغير ييش آزمون و متغير مستقل با استفاده از آناليز كوواريانس بانس

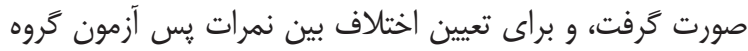
هاى تجربى و كنترل از آزمون تحليل كوواريانس (مانكووا و آنكوا)،

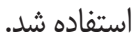

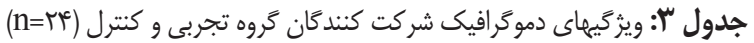

\begin{tabular}{|c|c|c|c|c|}
\hline شاخص توده بدنى & وزن (كيلوگرم) & قد (سانتى متر) & سن (سال) & گروه \\
\hline$r V / r \pm r$ & $V \Delta / r \pm q$ & $\mid \notin \varphi / V \pm \Delta$ & $s V / F \pm r$ & تجربى (r=1r) \\
\hline$r \xi / \xi \pm \Lambda$ & $r / r \pm r$ & $1 \varepsilon \Delta / r \pm r$ & $\xi \xi / \xi \pm V$ & كنترل (rn=I) \\
\hline
\end{tabular}

و تعيين مكان معنادار شدن آمارى اثر متغير مستقل روى هر يك از متغيرهاى وابسته، تحليل كواريانس تك متغيرى هر متغير بطور جداكانه انجام شد كه نتايج مربوطه در (جدول أ) آورده شده است. تجزيه تحليل داده ها نشان داد توزيع داده هاى ييش آزمون و پِ آزمون، در هر دو گَروه كنترل و تجربى نرمال بودهد و واريانس

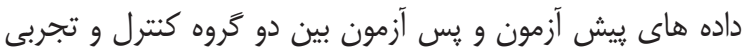
برابر است، و همجنين ييش فرض همخنى شيب ركر اسيون نيز برقرار

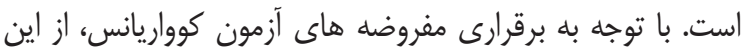

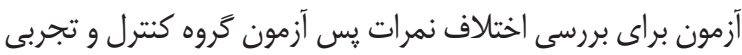

استفاده شد.
به منظور تعيين اثر كَروه بر اندازه هاى نمرات تعادل يس

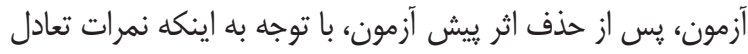

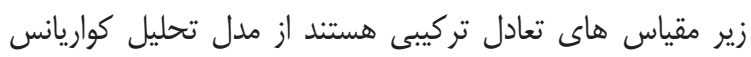

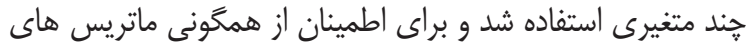

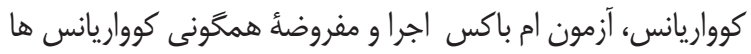

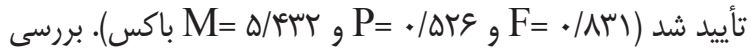
مفروضه برابرى واريانس هاى خطا، با آزمون لوين نشان داد كه

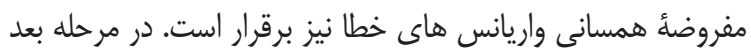
مقدار F تند متغيرى هاتلينگ محاسبه شد تا اثربخشى شيوه مداخله

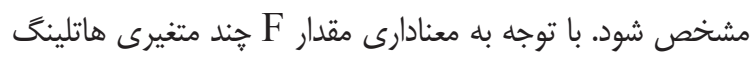

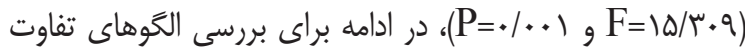

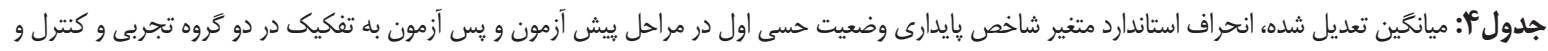
نتايج تحليل كوواريانس

\begin{tabular}{|c|c|c|c|c|c|c|c|}
\hline \multicolumn{3}{|c|}{ نتايج تحليل كواريانس } & \multicolumn{2}{|c|}{ كروه كنترل } & \multicolumn{2}{|c|}{ كروه تجربى } & \multirow{3}{*}{ متغير } \\
\hline \multirow[b]{2}{*}{ مجذور اتا } & \multirow[b]{2}{*}{ Pقدار P P P } & \multirow[b]{2}{*}{ Fقدار F F } & يّس آزمون & بيش آزمون & بِس آزمون & بيش آزمون & \\
\hline & & & ميانكَين土 انحراف & انحراف معيار & ميانكيند انحراف & ميانكَين | انحراف & \\
\hline .1 .9 & $\% \cdot / . r$ & $5 / 9 q$ & $q r / q u \pm r / l$ & $q . / q u \pm \varepsilon / V$ & $q r / V r \pm r /$. & $q \Psi / \mathcal{\varphi} \backslash \pm \Gamma / \Lambda$ & وضعيت حسى اول \\
\hline .1 .0 &.$/ . V$ & ה ג//r & $q . / / \mu \pm \varepsilon / \wedge$ & $q . / \kappa 8 \pm V / 1$ & $9 r / \lambda r \pm r / r$ & $9 r / 1 \cdot \pm r / q$ & وضعيت حسى دوم \\
\hline$\%$ & .199 &.$/ 11$ & $Q \Gamma / \varphi^{\prime} \Delta \pm r /$. & १)/VA $\pm \Delta / 1$ & Q $1 / \Delta F \pm r / c$ & $\Lambda 9 / 98 \pm \kappa / r$ & وضعيت حسى سوم \\
\hline $.1 \cdot 1$ & $\% . / . r$ & $\Delta / v$. & $\eta \pi / \varphi \pm 11 / r$ & $V / \propto F \pm I Q / q$ & $V c / q T \pm \mid r /$. & $q \pi / q \pi \pm / q / 4$ & وضعيت حسى جهارم \\
\hline .1 .1 & . & . /qv & $9 / / \% q \pm 1 N / r$ & $\Delta q / / F \pm W N / q$ & $q) / \cdot r \pm 1 F / q$ & $\Delta|/ \Delta| \pm \mid Q / 1$ & وضعيت حسى بنججم \\
\hline. & $\cdot / \Delta \Delta$ & צ & $\Delta Q / \wedge V \pm \pm r r / Q$ & $\Delta D / \mu \Phi \pm \Gamma \mu / \mu$ & $\Delta V / N{ }^{\mu} \pm I V / r$ & $r V / \mathcal{N} \pm r \Delta / r$ & وضعيت حسى ششم \\
\hline .1 &.$/ 4$ & $r / \pi \Lambda$ & $r V / r \Lambda \pm r / \mathcal{F}$ & $r \Delta / q) \pm \Delta / r$ & $\Gamma / / \mathcal{T} \cdot \pm \mu / \Lambda$ & $r \omega / \bar{q} \cdot \pm r / \varphi$ & لعادل تركيبي \\
\hline.$/ .1$ & $\cdot \pi \Delta$ & $\cdot / A V$ & $1 / \cdot r \pm \cdot / \cdot 1$ & $1 / \cdot r \pm \cdot / \cdot 1$ & $1 / \cdot f \pm \cdot / \cdot 1$ & $1 / \cdot r \pm . / \cdot 1$ & عملكرد سيسته حس \\
\hline $.1 . \mathrm{V}$ & $* \% . r$ & $\Delta / \Gamma)$ & $\cdot / \wedge \& \pm \cdot / 1$ & $\cdot / \Lambda f \pm \cdot / r$ & $\cdot / \wedge \Delta \pm \cdot / 1$ & $\cdot / v 9 \pm \cdot / r$ & عملكرد سيستم حسى بينايى \\
\hline.$/ .1$ & $\cdot / \mu F$ &.$/ 91$ & $\cdot / v q \pm \cdot / r$ & $\cdot / \mathrm{V} A \pm \cdot / r$ & $\cdot \mid q \mu \pm \cdot / r$ & $\cdot|\Delta| \pm \cdot / r$ & عملكرد سيستم حس وستيبولار \\
\hline .1 .1 & .199 & .199 & $1 / \cdot r \pm \cdot r$ & $1 / \cdot \Delta \pm \cdot / r$ & $1 / r \pm \cdot / /$ & $1 / \cdot \varphi \pm \cdot / r$ & \\
\hline
\end{tabular}

* * نماد معنادارى در سطح (• (P/ ) 
بافته هاى تحقيق حاضر با تحقيق كامينسكى و همكاران (T IV) آندى مغز (a-tDCS) مخ افراد سالمند نمى تواند باعث تسهيل يادگيرى تكليف تعادلى يويا شود همخوان نيست، احتمالاً دليل اين ناهمخوانى تعداد كم جلسات تحقيق فوق الذكر و متفاوت بودن نوع تكليف باشد (V)، در حالى كه نتايج اين تحقيق با يافته هاى كريخ و همكاران (T+IV) كه دريافتند يك جلسه تحريك مستقيم الكتريكى

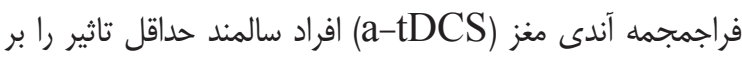
كنترل وضعيت ايستاده سالمندان دارد (أ). و با تحقيق يوسفى و

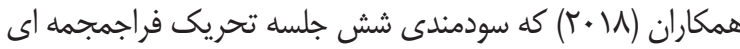

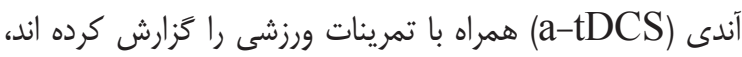

همخوان است (1) (1).

در توجيه نتايج بدست أمده مى توان كفت كه تحريك

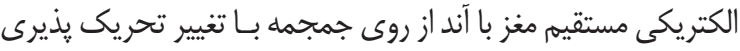

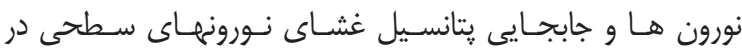

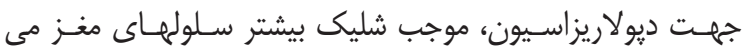
شود، اولين ساز و كار عمل tDCS در سطح سلولى، تغيير يتانسيل غشاء سلول مى باشد. فعاليت و تحريك يذيرى قشرى توسط تحريك آندى افزايش و توسط تحريك كاتدى كاهش مى يابد (TV). مطالعات حيوانى نشان مى دهد تغييرات در تحريك يذيرى، هم در نرخ فعاليت خودبخودى سلول و هم در ياسخ دهى به ورودى هاى

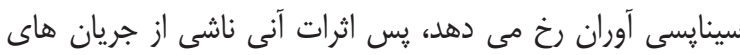

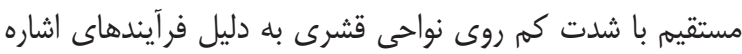

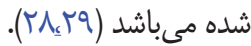
اما ساز وكار عمل tDCS به تنهايى به تغيير يتانسيل غشاء سلول عصبى محدود نمى شود. در حقيقت مطالعات بعدى نشان داد tDCS مى تواند باعث تغيير در سينايس ها شود كه اين عمل بهل

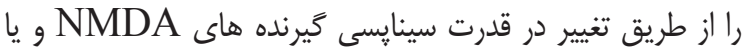
GABA قشرى (كورتكس) و مسيرهاى قشرى - نخاعى نيز تاثير گذار است

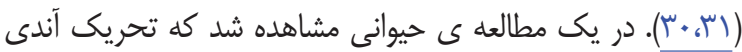
قشر حركتى باعث افزايش ماندكار رتانسيل هاى تحريكى يس

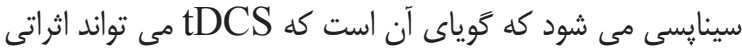

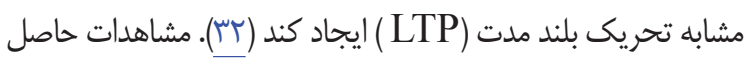
از تحريك اعصاب محيطى و طناب نخاعى نيز نشان داد كه جريان مستقيم داراى اثرات غير سينايسى نيز مى باشد كه ممكن است به به دليل تغيير گذرا در خَّالى كانال هاى يروتئينى زير محل الكترودها

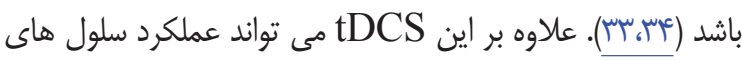

تجزيه تحليل نتايج نشان داد كه تحريك الكتريكى مخ همراه با تمرينات تعادل به طور معنادارى ڤايدارى سالمندان در وضعيت

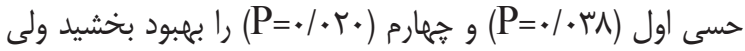

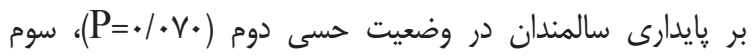

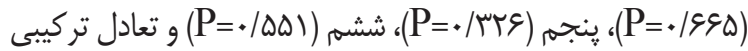
(P= اثر معنادار نداشت. همجنين تحريك الكتر يكى مخ همراه با تمرينات تعادل، عملكرد كنترل وضعيت ايستاده سيستم بينايى

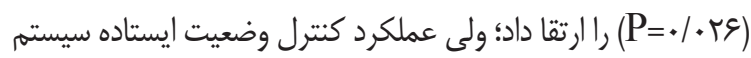
حس :ييكرى (

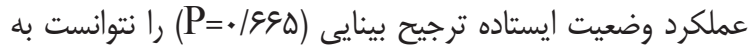
طور معنادار ارتقا دهد. اندازه اثر محاسبه شده (مجذور جزئى اتا) نشان مى دهد كه حداكثر ده درصد تغيير متغير وابسته مربوط به اثر تى

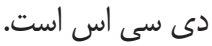

\section{هحث}

نتايج تحقيق، حاكى از تاثيرمعنادار تحريك الكتريكى مخ با جريان مستقيم بر متغيرهاى پايدارى كنترل وضعيت ايستاده در وضعيت حسى اول (جشم هاى بسته و سطح اتكاى ثابت) و وضعيت حسى جهارم (جشم هاى باز و سطح اتكا ثابت) بود، تاثيرات اين تحريك بر شاخص يايدارى در وضعيت حسى دوم (حذف اطلاعات

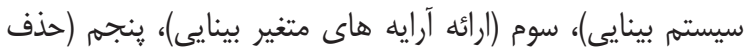
اطلاعات سيسته بينايى و ارايه آرايه هاى متغير حس ييكرى) و ششم (ارايه آرايه هاى متغير سيستم بينايى و حس عمقى) معنادار نبود. همجنين يافته ها نشان داد مداخله توانسته است نمره عملكرد كنترل وضعيت ايستاده با حس بينايى را بطور جشمخيرى بهبود بخشد و توانايى سالمندان در استفاده مؤثر از درون دادهاى حس بينائ بينايى راني

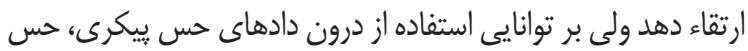
دهليزى و ترجيح بينايى تاثير معنادار نداشته است. به بيان ديخر؛ نتايج تحقيق، حاكى از اين است كه تحريك الكتريكى واقعى مخ با جريان مستقيم همراه با تمرينات تعادلى طى ینج جلسه توانسته است جنبه هايى از كنترل تعادل سالمندان كه متكى بر عملكرد وضعيت ايستاده سيتم بينايى است را بهبود بخشد. اين يافته ها احتمالا دلالت بر اين دارد كه تحريك مخ باعث تسهيل يادگيرى مهارت هاى حركتى

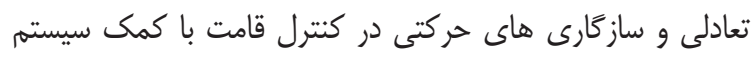

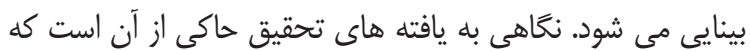
ار يازده متغير مورد بررسى، صرفاً سه متغير تحت تاثير مداخله قرار كرفته اند كه نشان دهنده اين موضوع مى تواند باشد كه تاثير مداخله

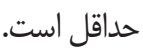


اختلالات راه رفتن است بنابراين در تحقيقات آينده سالمندانى كه با افزايش خطر افتادن مواجه هستند بايد در مركز توجه قرار بحيرند.

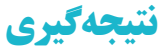

نتايج اين تحقيق نشان داد كه تحريك الكتريكى مخ با جريان مستقيم الكتريكى همراه با تمرينات تعادلى بر برخى از متغيرهاى پإيدارى و عملكرد سيستم هاى حسى كنترل وضعيت ايستاده و

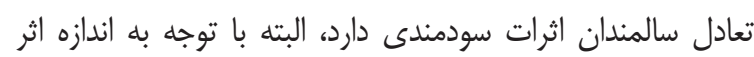

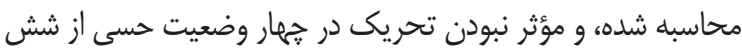
وضعيت حسى مى توان كفت اين تاثير جزئى بوده است و با توجه به بإيين بودن حجم نمونه يُوهش حاضر؛ يُوهشكران در تعميم

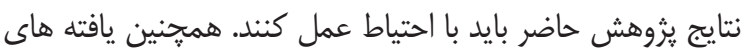
اين تحقيق احتمالاً دلالت بر اين دارد كه تحريك مخ باعث باطن تسهيل

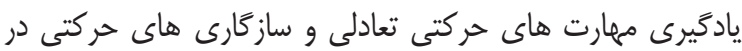
كنترل قامت با كمك سيسته بينايى مى شود.

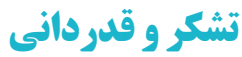 \\ از تمامى شركت كننده هاى تحقيق و مسئولين محترم دانشعاه و مركز جامع توانبخشى جمعيت هلال احمر تهران كه در كردآورى اين يثوهش ما را يارى نمودند كمال تشكر و قدردانى را داريم.}

\section{Refrences}

1. Takakusaki K. Functional neuroanatomy for posture and gait control. Journal of movement disorders. 2017; 10 (1):1.

2. Solis-Escalante T, van der Cruijsen J, de Kam D, van Kordelaar J, Weerdesteyn V, Schouten AC. Cortical dynamics during preparation and execution of reactive balance responses with distinct postural demands. NeuroImage. 2019; 188: 557-71.

3. Doumas M, Krampe RT. Adaptation and reintegration of proprioceptive information in young and older adults' postural control. Journal of neurophysiology. 2010; 104 (4):1969 - 77.

4. Craig CE, Doumas M. Anodal transcranial direct current stimulation shows minimal, measurespecific effects on dynamic postural control in young and older adults: a double blind, sham-controlled study. PloS one. 2017; 12 (1): e0170331.

5. Bahramnezhad F, Asadi Noughabi AA, Farokhnezhad Afshar P, Marandi S. Exercise and
عصبى را به وسيله ى تغييرات عصبى- شيميايى تحت تاثير قرار دهد. به عنوان مثال ديده شده است كه بعد از اعمال tDCS آندى ميزان Myo inositol (يك قند كاربوسيكليك، كه در مغز و ديخر بافتهاى پِتانداران فراوان است و در انتقال ييام سلولى در ياسخكَويى به انواع هورمون ها، انتقال دهنده هاى عصبى و عوامل رشد دخالت مى كند و در تنظيم اسمزى مؤثر است) مغزى به طور واضحى افزايش ييدا مى كند (بس، هـ"). يكى از محدوديت هاى تحقيق حاضر اين بود كه در مطالعه حاضر، از معيارهاى رفتارى براى ارزيابى يادگّيرى حركتى در إنى

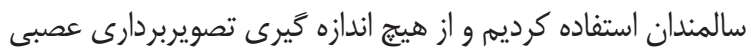

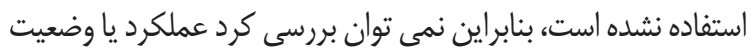

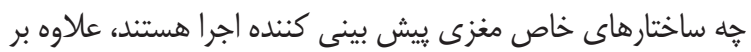

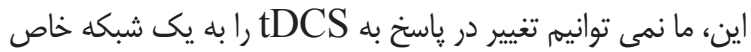
مغز مرتبط كنيه. براى درك بهتر از ارتباطات عصبى يادكّيرى كنترل

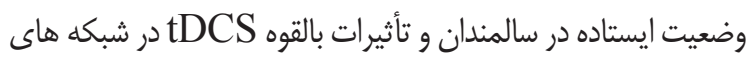
عصبى، مطالعات ديخرى كه ارزيابى هاى عصبى فيزيولوزيكى فعال سازى مغز را با ارزيابى هاى رفتارى تركيب كند مورد نياز است.

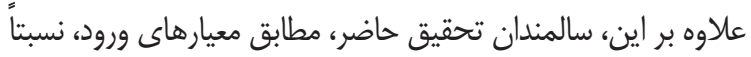
دقيق انتخاب شدند و بنابراين مى توانند سالم و فعال در نظر كرفته

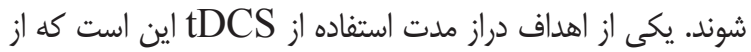

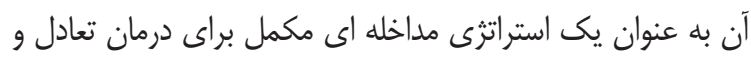

Quality of Life in Patients with Chronic Heart Failure. 2013; 2 (2):5.

6. Yitayeh A, Teshome A. The effectiveness of physiotherapy treatment on balance dysfunction and postural instability in persons with Parkinson's disease: a systematic review and meta-analysis. BMC sports science, medicine and rehabilitation. 2016; 8 (1):17.

7. Kaminski E, Hoff M, Rjosk V, Steele CJ, Gundlach C, Sehm B, et al. Anodal transcranial direct current stimulation does not facilitate dynamic balance task learning in healthy old adults. Frontiers in human neuroscience. 2017; 11:16.

8. Nabavi SH, Alipour F, Hejazi A, Rashedi VJmjomuoms. Relationship between social support and mental health in older adults. 2014; 57 (7): 841 - 6.

9. Beyaert C, Vasa R, Frykberg GE. Gait poststroke: pathophysiology and rehabilitation strategies. Neurophysiologie Clinique/Clinical Neurophysiology. 2015; 45 (4-5): 335 - 55. 
10. Schoneburg B, Mancini M, Horak F, Nutt JG. Framework for understanding balance dysfunction in Parkinson's disease. Movement disorders. 2013; 28 (11): 1474 - 82.

11. Huisinga JM, Yentes JM, Filipi ML, Stergiou N. Postural control strategy during standing is altered in patients with multiple sclerosis. Neuroscience letters. 2012; 524 (2):124 - 8.

12. Howard-Wilsher S, Irvine L, Fan H, Shakespeare $\mathrm{T}$, Suhrcke M, Horton S, et al. Systematic overview of economic evaluations of healthrelated rehabilitation. Disability and Health Journal. 2016; 9 (1): 11 - 25.

13. Jacobs J, Horak F. Cortical control of postural responses. Journal of neural transmission. 2007; 114 (10):1339.

14. Thair H, Holloway AL, Newport R, Smith AD. Transcranial direct current stimulation (tDCS): a beginner's guide for design and implementation. Frontiers in neuroscience. 2017; 11: 641.

15. Zhu FF, Yeung AY, Poolton JM, Lee TM, Leung GK, Masters RS. Cathodal transcranial direct current stimulation over left dorsolateral prefrontal cortex area promotes implicit motor learning in a golf putting task. Brain stimulation. 2015; 8 (4): 784-6.

16. Parasuraman R, McKinley RA. Using noninvasive brain stimulation to accelerate learning and enhance human performance. Human factors. 2014; 56 (5): 816 - 24.

17. Leenus D, Cuypers K, Vanvlijmen D, Meesen R. The effect of anodal transcranial direct current stimulation on multi-limb coordination performance. Neuroscience. 2015; 290: 11-7.

18. Yosephi MH, Ehsani F, Zoghi M, Jaberzadeh S. Multi-session anodal tDCS enhances the effects of postural training on balance and postural stability in older adults with high fall risk: primary motor cortex versus cerebellar stimulation. Brain stimulation. 2018; 11 (6): 1239 - 50.

19. Keel JC, Smith MJ, Wassermann EM. A safety screening questionnaire for transcranial magnetic stimulation. Clinical neurophysiology. 2001; 112 (4): 720 .

20. Birmingham Uo. TDCS and TACS Safety Questionnaire [cited 2015]. Available from: prism.bham.ac.uk/downloads/TDCS_Safety_ Qs_ConsentForm_30092015.pdf.

21. seyedian $\mathrm{m}$, falah $\mathrm{m}$, novrozyan $\mathrm{m}$, najat $\mathrm{s}$, dlavar a, ghasemzadeh h. Preparation and validation of the Persian version of Mini Mental Status Evaluation (MMSE). journal of medical council of islamic republic of iran. 2007; 25 (4): 408-14. eng.

22. Whitney S, Roche J, Marchetti G, Lin C-C, Steed D, Furman G, et al. A comparison of accelerometry and center of pressure measures during computerized dynamic posturography: a measure of balance. Gait \& posture. 2011; 33 (4): $594-9$.

23. Couillandre A, Duque Ribeiro MJ, Thoumie P, Portero P. Changes in balance and strength parameters induced by training on a motorised rotating platform: a study on healthy subjects. Ann Readapt Med Phys. 2008 Mar; 51 (2): 5973. PubMed PMID: 18207276. Epub 2008/01/22. eng fre.

24. Folstein MF, Folstein SE, McHugh PR. "Minimental state". A practical method for grading the cognitive state of patients for the clinician. J Psychiatr Res. 1975 Nov; 12 (3):189 - 98. PubMed PMID: 1202204. Epub 1975/11/01. eng.

25. Thair H, Holloway A, Newport R, Smith A. Transcranial direct current stimulation (tDCS): a beginner's guide for design and implementation. Front Neurosci 2017; 11: 641. PUBMED.

26. Reyes A, Salomonczyk D, Teo W-P, Medina LD, Bartlett D, Pirogovsky-Turk E, et al. Computerised Dynamic Posturography in Premanifest and Manifest individuals with Huntington's Disease. Scientific reports. 2018; 8 (1): 14615.

27. Nitsche MA, Paulus W. Excitability changes induced in the human motor cortex by weak transcranial direct current stimulation. The Journal of physiology. 2000; 527 (3): 633 - 9.

28. Priori A, Berardelli A, Rona S, Accornero N, Manfredi M. Polarization of the human motor cortex through the scalp. Neuroreport. 1998; 9 (10): 2257 - 60 .

29. Bikson $M$, Inoue $M$, Akiyama $H$, Deans JK, Fox JE, Miyakawa H, et al. Effects of uniform extracellular DC electric fields on excitability in rat hippocampal slices in vitro. The Journal of physiology. 2004; 557 (1): 175-90.

30. Liebetanz D, Nitsche MA, Tergau F, Paulus W. Pharmacological approach to the mechanisms of transcranial DC-stimulation-induced after- 
effects of human motor cortex excitability. Brain. 2002; 125 (10): 2238 - 47.

31. Nitsche M, Fricke K, Henschke U, Schlitterlau A, Liebetanz D, Lang N, et al. Pharmacological modulation of cortical excitability shifts induced by transcranial direct current stimulation in humans. The Journal of physiology. 2003; 553 (1): 293 - 301 .

32. Fritsch B, Reis J, Martinowich K, Schambra HM, Ji Y, Cohen LG, et al. Direct current stimulation promotes BDNF-dependent synaptic plasticity: potential implications for motor learning. Neuron. 2010; 66 (2): 198 - 204.

33. Ardolino G, Bossi B, Barbieri S, Priori A. Non-synaptic mechanisms underlie the aftereffects of cathodal transcutaneous direct current stimulation of the human brain. The Journal of physiology. 2005; 568 (2): 653 - 63.

34. Cogiamanian F, Vergari M, Pulecchi F, Marceglia S, Priori A. Effect of spinal transcutaneous direct current stimulation on somatosensory evoked potentials in humans. Clinical Neurophysiology. 2008; 119 (11): 2636 - 40.

35. Rango M, Cogiamanian F, Marceglia S, Barberis B, Arighi A, Biondetti P, et al. Myoinositol content in the human brain is modified by transcranial direct current stimulation in a matter of minutes: A 1H-MRS study. Magnetic Resonance in Medicine: An Official Journal of the International Society for Magnetic Resonance in Medicine. 2008; 60 (4): 782 - 9. 